\title{
Targeted drug therapy to provide effective and localised anticoagulation without impairing haemostasis
}

Xiaowei Wang ${ }^{1,2}$, Donny Hanjaya-Putra ${ }^{3}$, Carolyn Haller ${ }^{3}$, Amy Kate Searle $^{1}$, Karlheinz Peter ${ }^{1,2}$, Elliot L. Chaikof ${ }^{3}$

${ }^{1}$ Atherothrombosis and Vascular Biology, Baker Heart \& Diabetes Institute, Melbourne, Victoria, Australia; ${ }^{2}$ Department of Medicine, Monash University, Victoria, Australia; ${ }^{3}$ Beth Israel Deaconess Medical Center (BIDMC), Harvard Medical School, Boston, Massachusetts

\section{INTRODUCTION}

- Current dual combination therapy using anti-platelet; anti-thrombotic; and/or anti-coagulation agents offers the promise of treatment and improved thrombotic protection

- Substantial risk of major bleeding hampers widespread use

\section{METHODS}

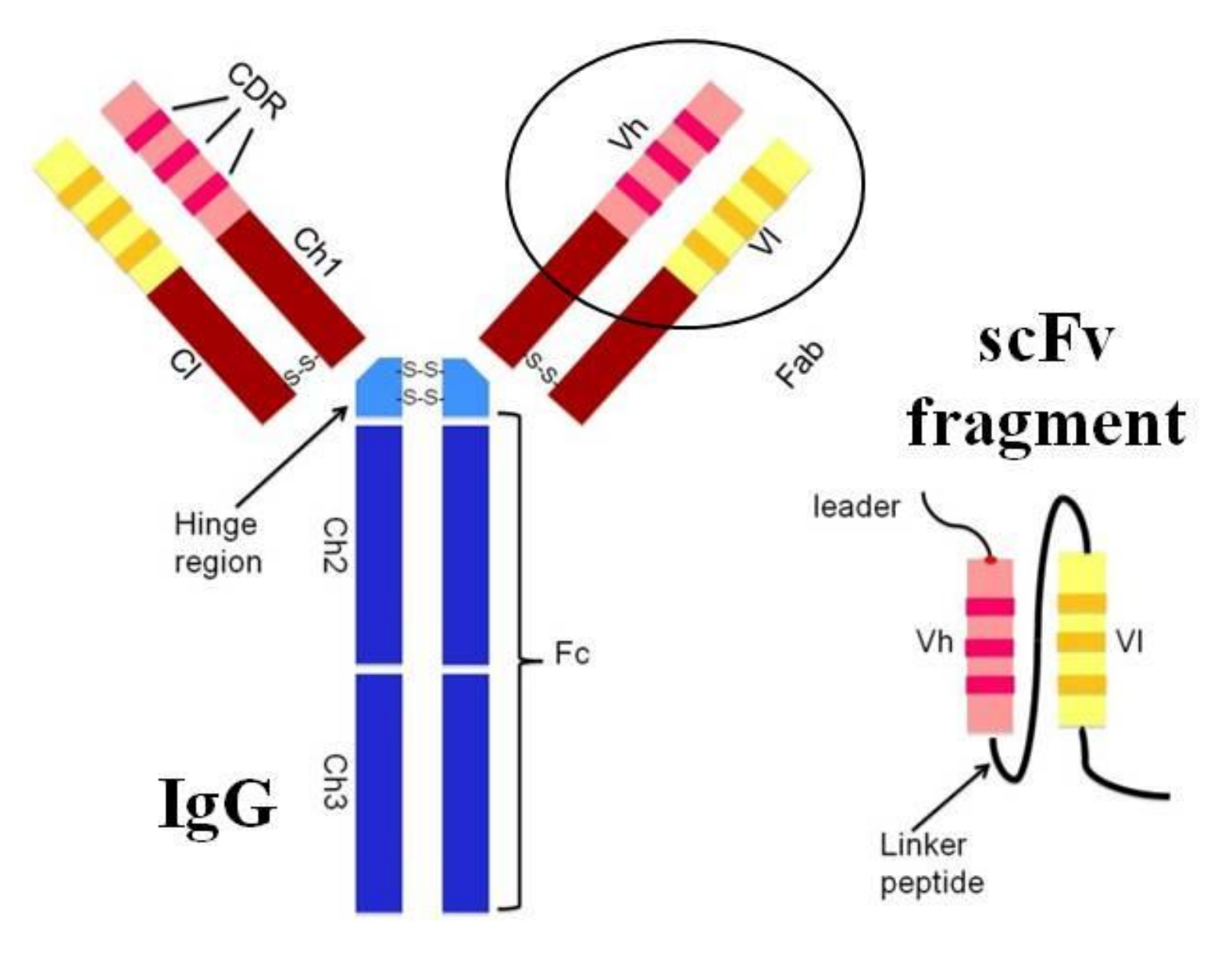

- Single chain antibody

- Targeting blocks activated GPIlb/Illa complex on activated platelets (scFvTarg)

○ Non-binding mutated control (scFv Non-targ)

- Tick anticoagulant peptide (TAP)

- Potent direct inhibitor of FXa

- $\mathrm{scFV}$ Targ + TAP = Targ-TAP

- scFvNon-targ + TAP = Non-targ-TAP

\section{RESULTS}

Targ-TAP binds to activated platelets and retains anti-FXa activity after fusion

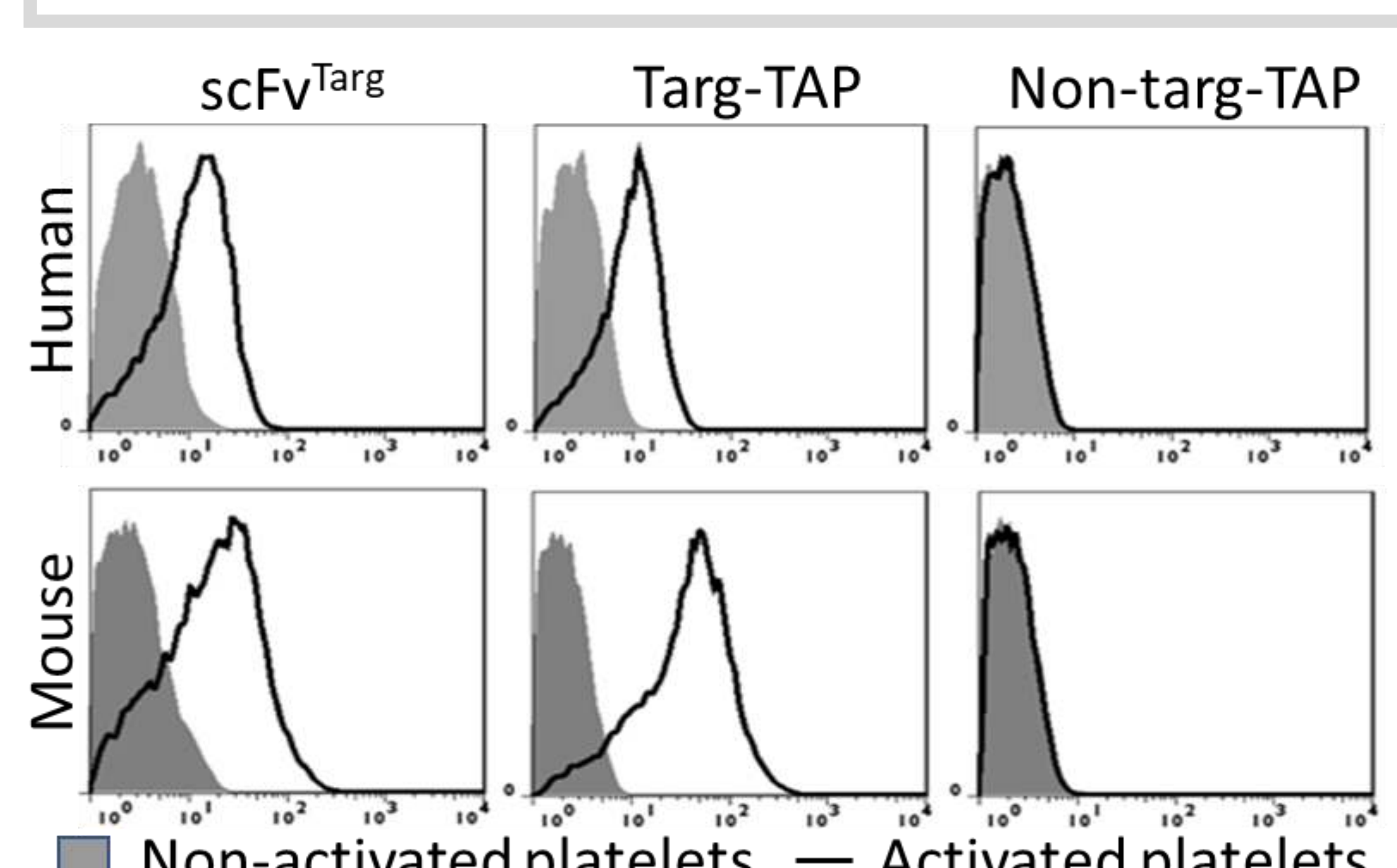

$\square$ Non-activated platelets - Activated platelets

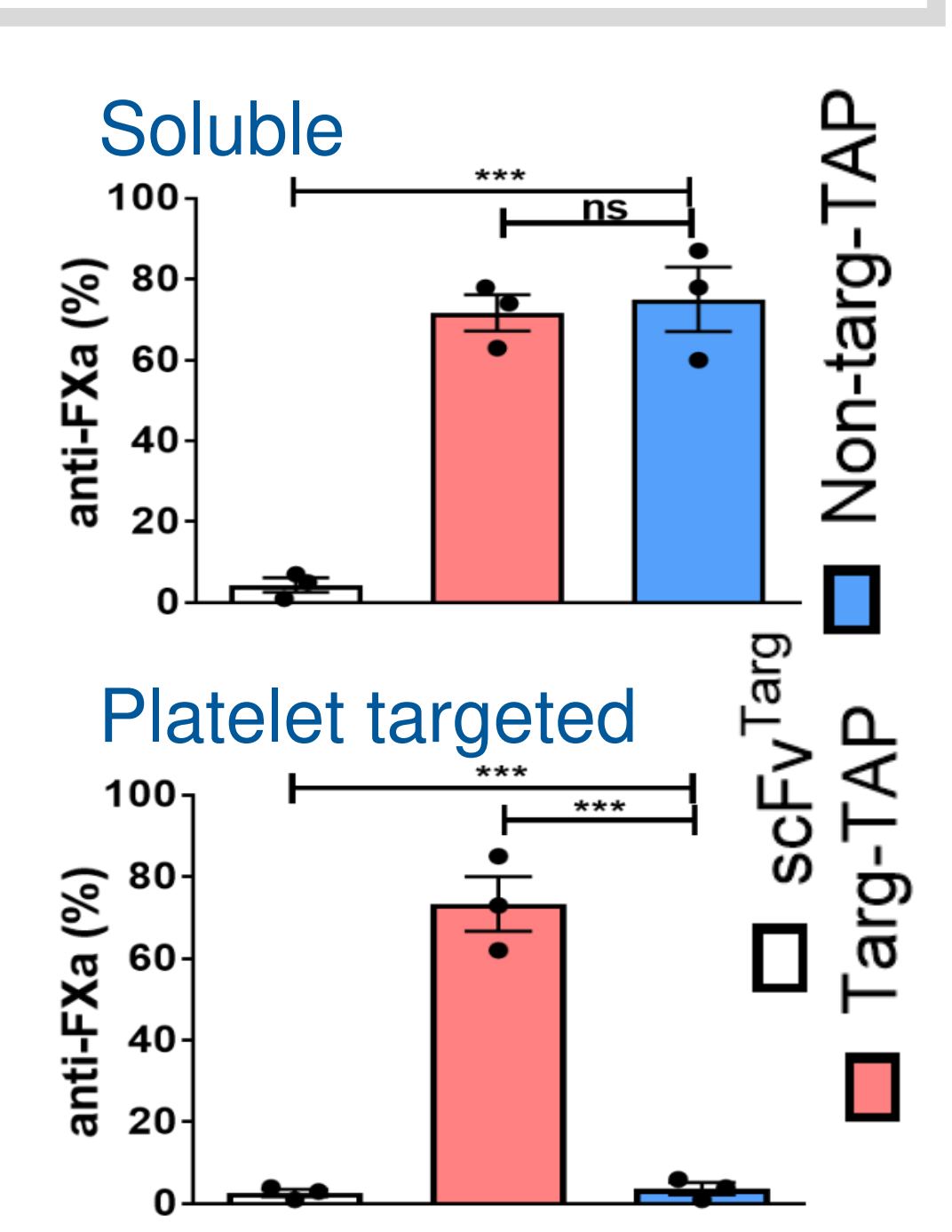

\section{Targ-TAP prevents thrombosis in vitro}

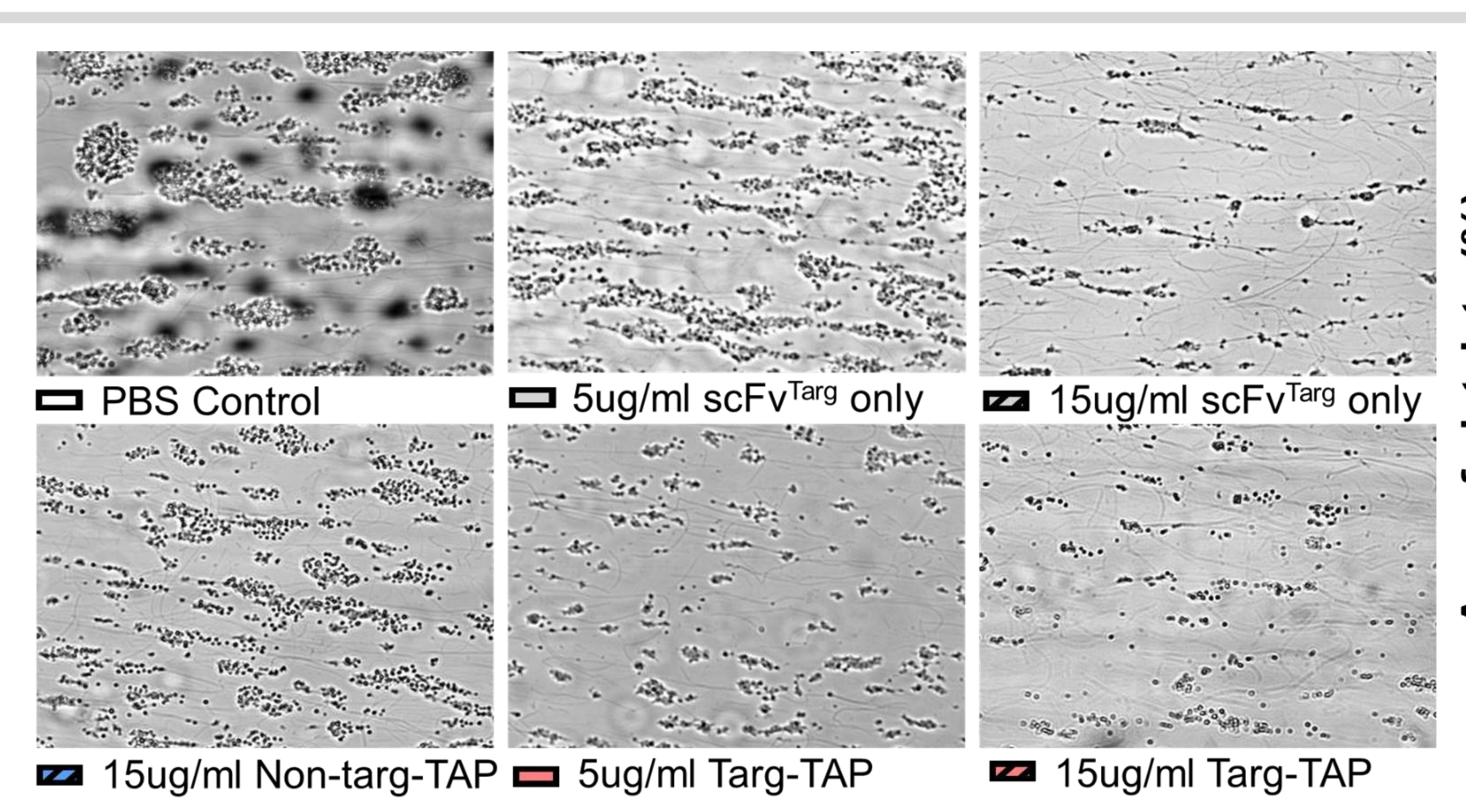

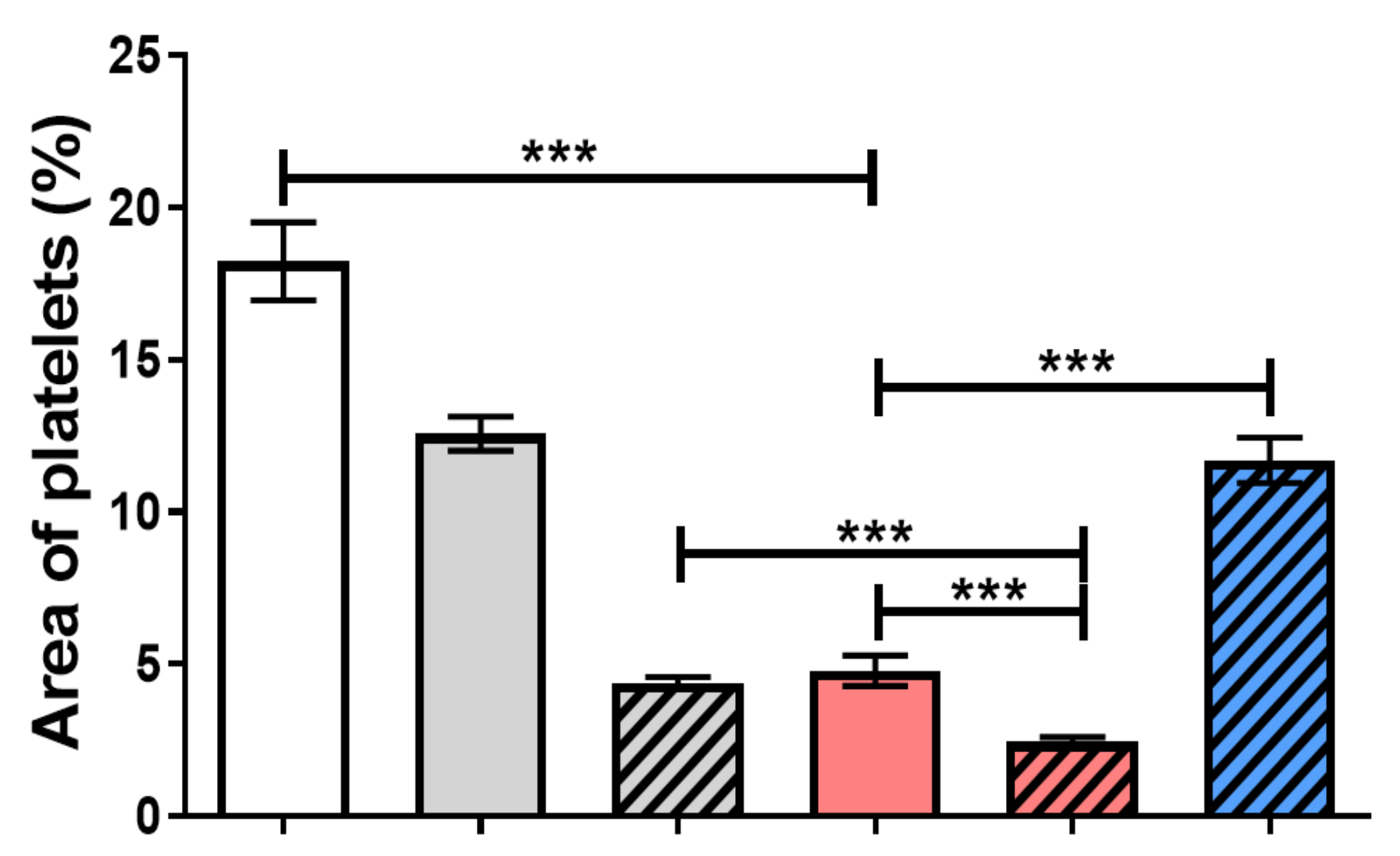

Targ-TAP colocalises with CD42b

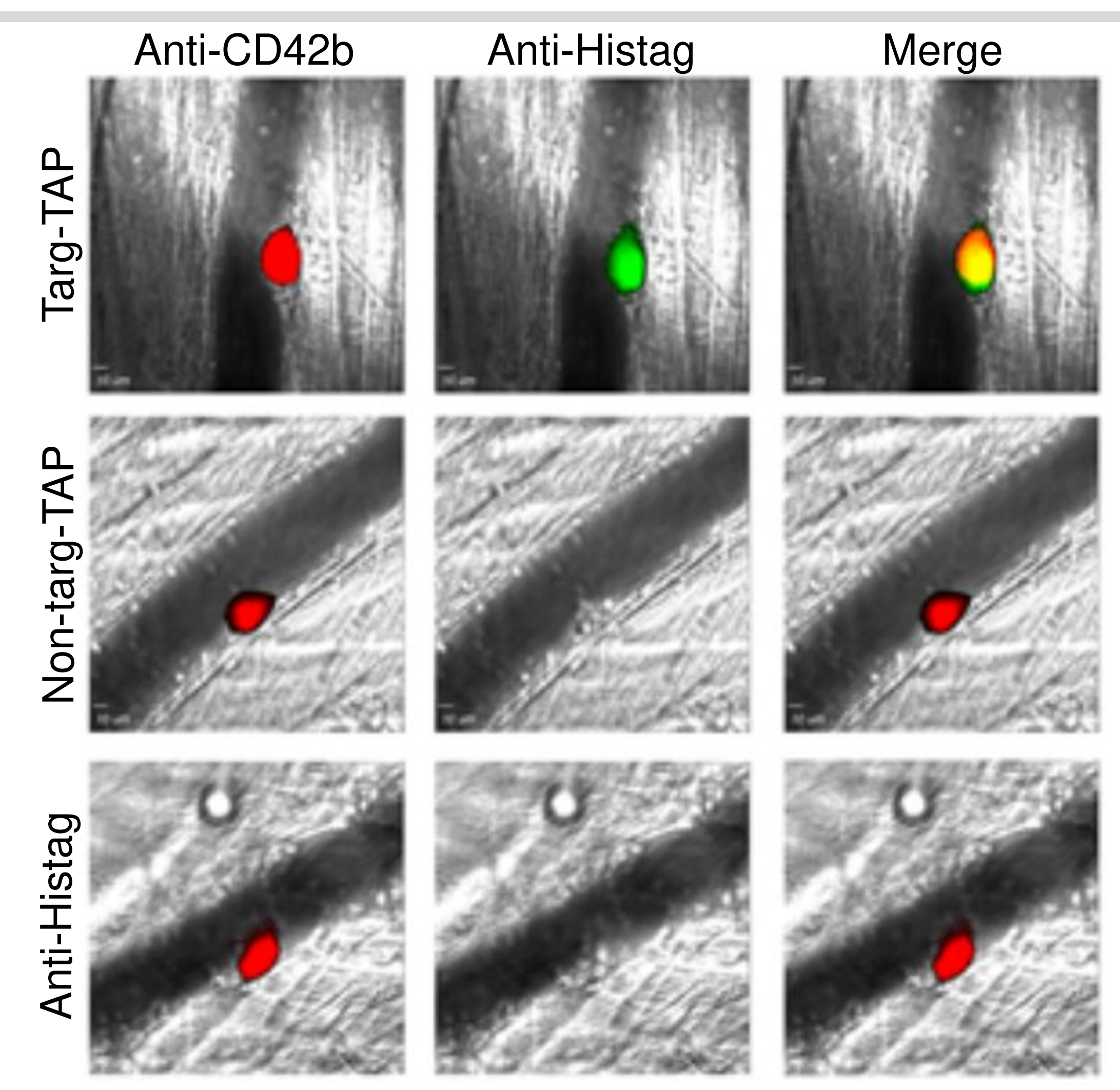

Targ-TAP binds after sealing layer of platelets

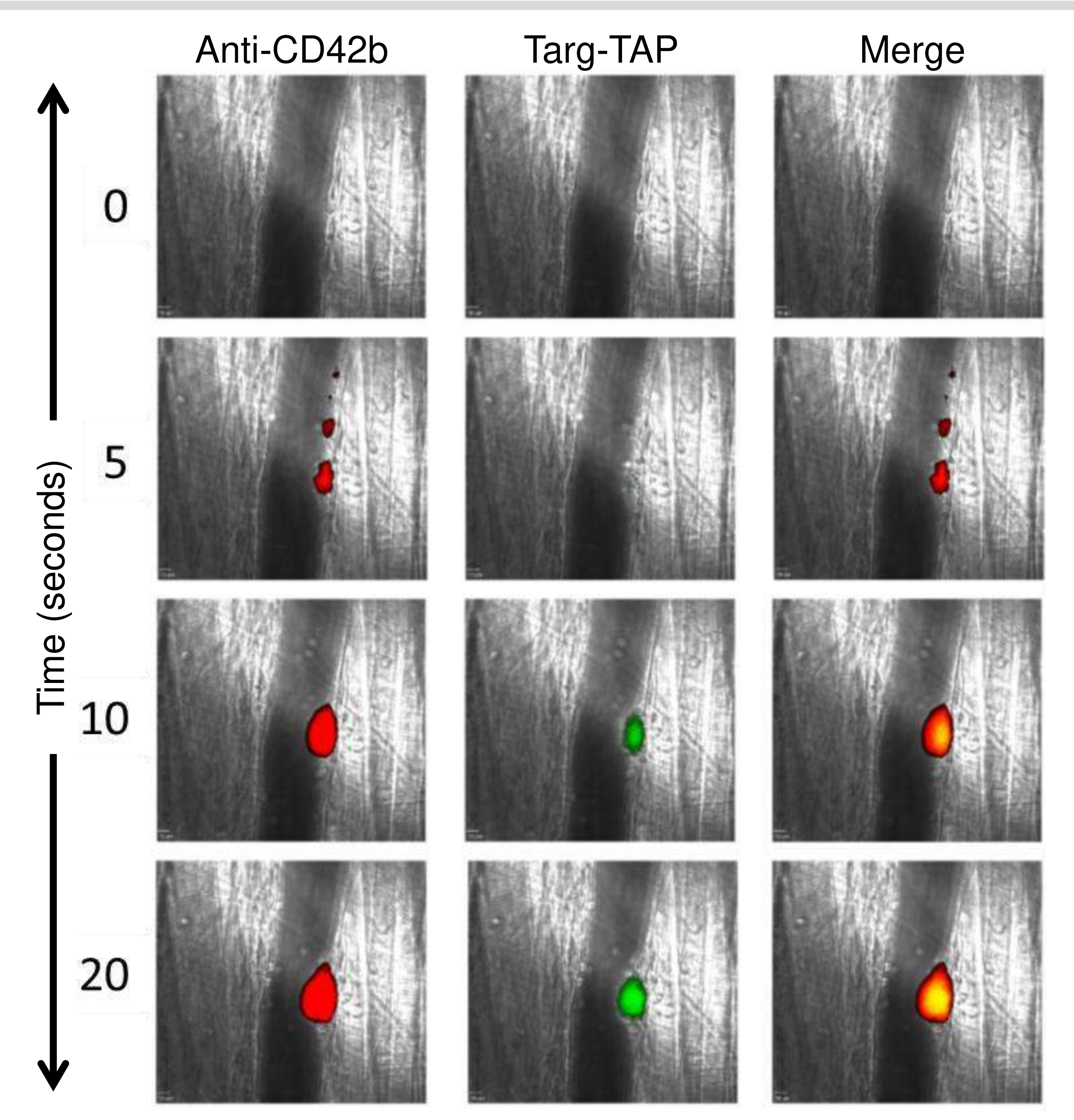

xiaowei.wang@baker.edu.au
Targ-TAP increases time to occlusion without bleeding in vivo

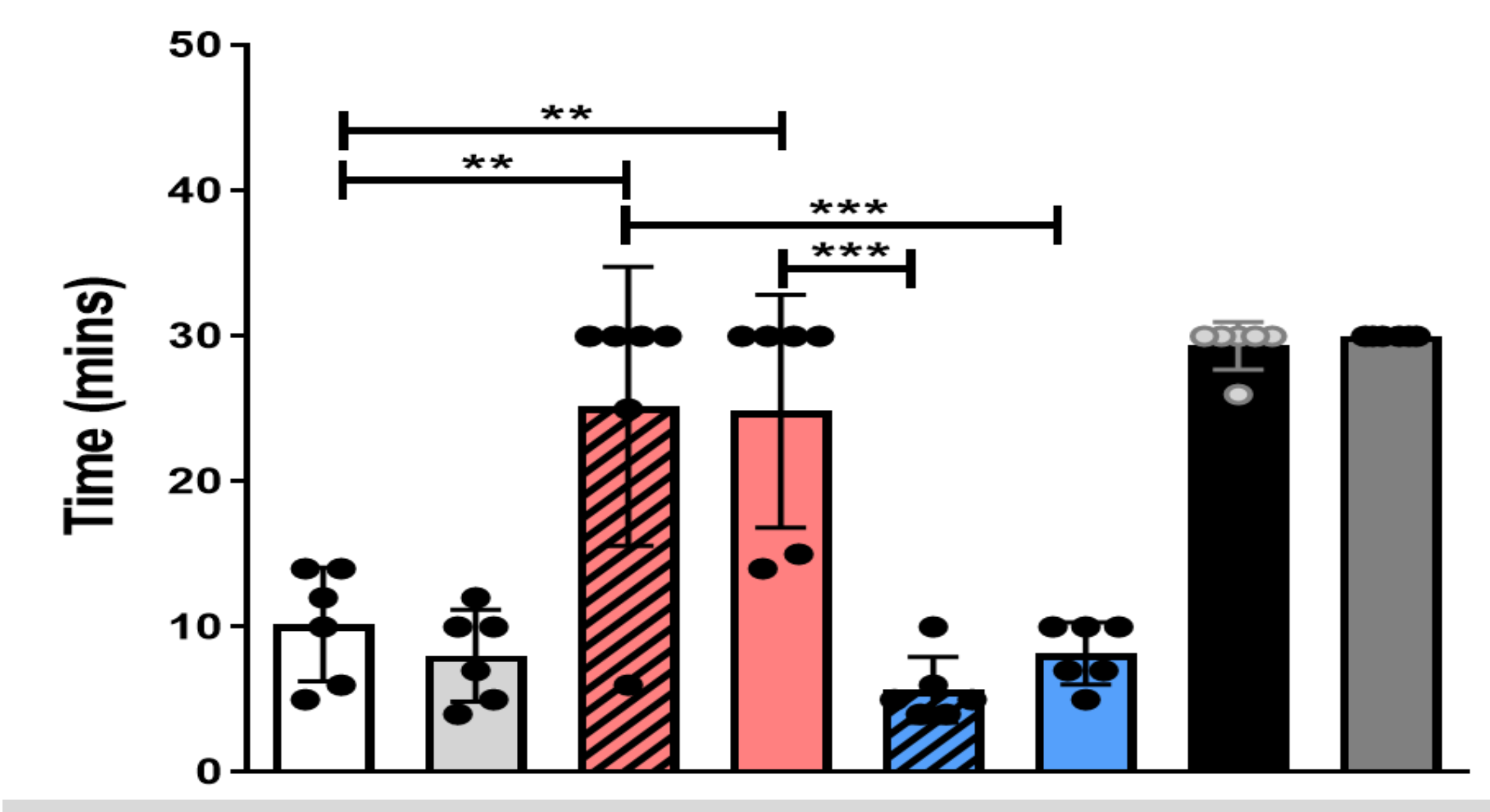

Subcutaneous prophylaxis approach (arterial)
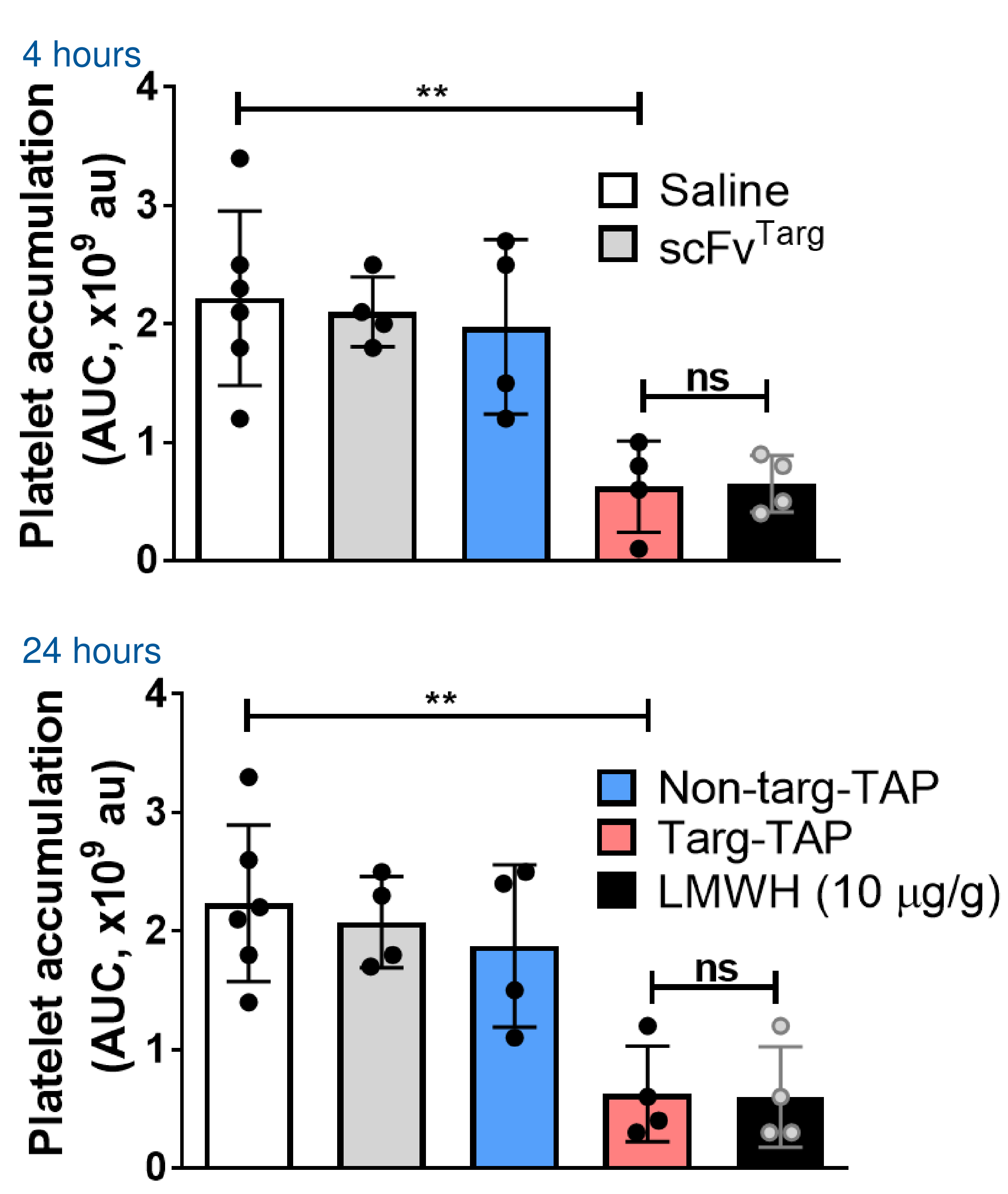

CONCLUSION

Activated platelet targeted TAP

- Prevents thrombosis in vitro and in vivo

- Overcomes bleeding complications

- Enables prophylactic strategy to be employed
Subcutaneous prophylaxis approach (venous)
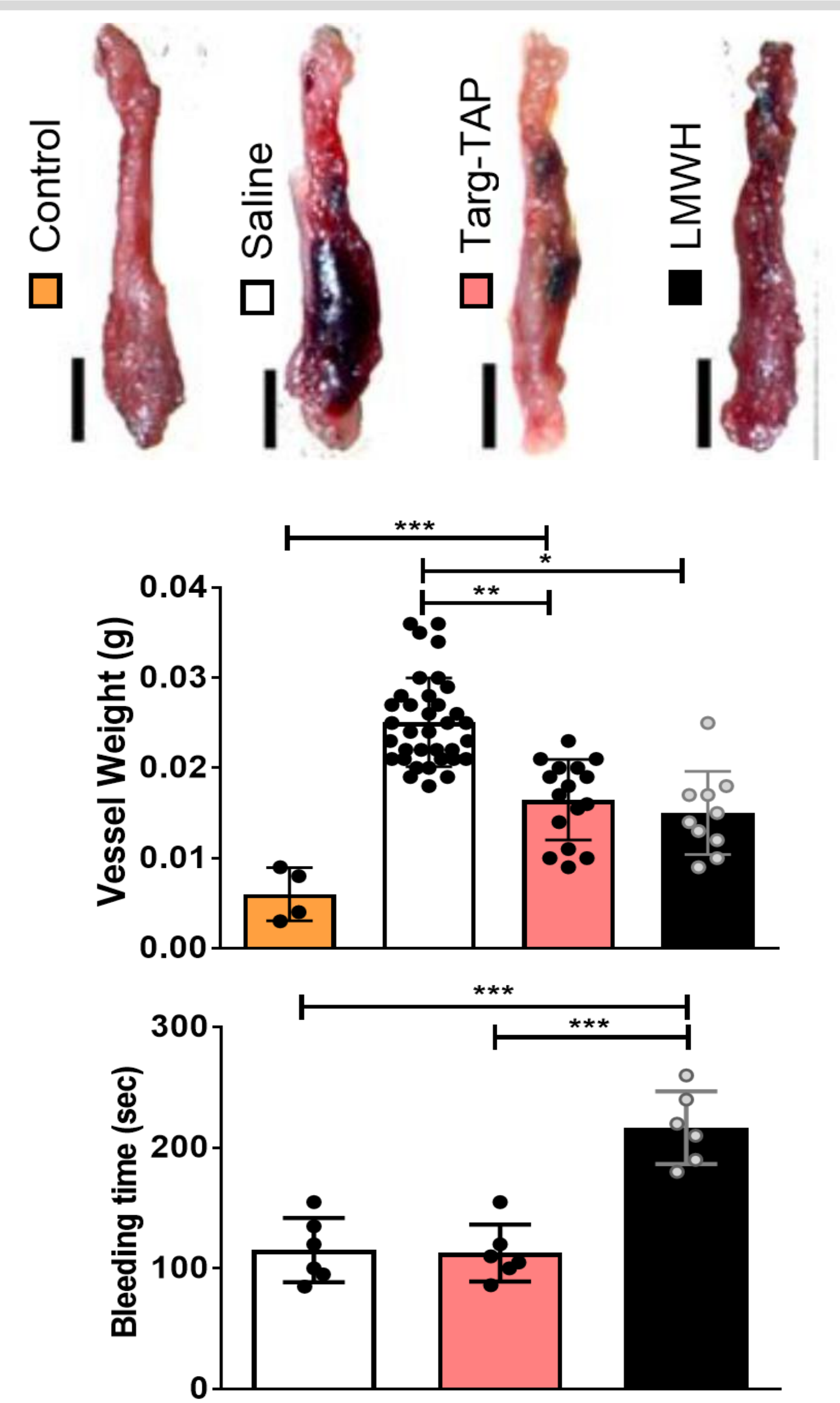